\title{
Towards a consistant safety format of steel beam-columns: application of the new interaction formulae for ambient temperature to elevated temperatures
}

\author{
P.M.M. Vila Real†^, N. Lopes \\ Department of Civil Engineering, University of Aveiro, 3810 Aveiro, Portugal \\ L. Simões da Silva $\dagger$ \\ Department of Civil Engineering, University of Coimbra, 3030-290 Coimbra, Portugal \\ P. Piloto† \\ Department of Mechanical Engineering, Polytechnic of Bragança, Bragança, Portugal \\ J.-M. Franssen $\dagger$ \\ Department M\&S, University of Liege, Liege, Belgium \\ (Received June 2, 2003, Accepted November 5, 2003)
}

\begin{abstract}
Two new formulae for the design of beam-columns at room temperature have been proposed into Eurocode 3, prEN 1993-1-1 (2002), and are the result of great efforts made by two working groups that followed different approaches, a French-Belgian team and an Austrian-German one. Under fire conditions the prEN 1993-1-2 (structural fire design) presents formulae, for the design of beam-columns based on the prENV 1993-1-1 (1992). In order to study the possibility of having, in part 1-1 and part 1-2 of the Eurocode 3, the same approach, a numerical research was made using the finite element program SAFIR, developed at the University of Liege for the study of structures subjected to fire.
\end{abstract}

Key words: beam-column; buckling; lateral-torsional-buckling; fire; Eurocode 3; numerical modelling.

\section{Introduction}

Steel beam-columns under bending and axial compression are checked for safety in fire conditions using interaction formulae that combine their separate resistances in axial compression or in bending. In the context of Eurocode 3, and under fire loading, the current draft of Part 1.2 of EC3 (prEN 1993-1-2, 2002) adopts the interaction formulae that appear in the European pre-standard for normal design, ENV

$\dagger$ Professor

$\ddagger$ Student 
1993-1-1 (1992), simply replacing the effective yield strength and the Young Modulus by their values at elevated temperature as well as the factor $\phi$ and the imperfection factor $\alpha$. As will be shown in detail later (see Eqs. (14) and (15)), this formulae is denoted here "prEN 1993-1-2".

Simultaneously, the project team involved in the conversion phase from ENV to EN of Part 1.1 has recently revised these interaction formulae at room temperature (prEN 1993-1-1, 2002). The reasons for this change were the complexity and lack of a physical rationale behind the interaction formulae of ENV 1993-1-1 (1992). Two alternative proposals were adopted that specifically implement the concepts of amplification factor and equivalent uniform bending moment. The proposal made by the FrenchBelgian team (Villette et al. 2000, Boissonnade et al. 2002) is referred in prEN 1993-1-1 (Greiner 2001) as "Method 1", and the Austrian-German group as "Method 2".

Under fire conditions and for the cases where the failure mode is in the plane of loading, axially and eccentrically loaded columns were studied by Franssen et al. (1995, 1996, 1998), who proposed a procedure for the design of columns under fire loading, later adopted by EC3 (EUROCODE 3, 2002). Analogously, Vila Real et al. $(1999,2001,2003)$ studied the problem of lateral torsional buckling of beams under fire loading, and equally proposed a design expression also adopted by EC3 (EUROCODE 3, 2002). These two proposals are thus part of the "prEN 1993-1-2" formulae, but it is also possible to take them into account and introduce them in the "Method 1" and "Method 2" formulae.

It is the objective of the present paper to propose a consistent safety check for the stability of beamcolumns under fire loading, by adapting the newly proposed interaction equations for cold design to fire design. More specifically, using the specialised finite element code SAFIR (Franssen 2003), results of second-order analysis, including imperfections, for a range of lengths, levels of axial force and loading cases, are compared with the codified interaction formulae from Part 1.2 of EC3 (EUROCODE 3, 2002) (here denoted "prEN 1993-1-2") and the proposed adaptation to fire loading of EC3, Methods 1 and Method 2, henceforth denoted "Method 1, fi" and "Method 2, fi". Finally, the safety of these proposals is discussed and established.

\section{Numerical model}

\subsection{Basic hypothesis}

The program SAFIR (Franssen 2003) was chosen to carry out the numerical simulations. This is a finite element code for geometrical and material non-linear analysis, specially developed at the University of Liege for studying structures subjected to fire.

Uniform temperature in the cross-section has been used so that comparison between the numerical results and the eurocodes could be made. In this paper the temperature used was $600{ }^{\circ} \mathrm{C}$, which safely represents the majority of practical situations.

The study takes in to account the possibility of lateral-torsional buckling or full restraint. In the beamcolumns without lateral torsional-bucking, the simulation was made with a $2 \mathrm{D}$ beam finite element, whereas to consider lateral torsional-buckling, a three-dimensional (3D) beam element was selected. The element is based on the following formulations and hypotheses:

- Displacement type element in a total co-rotational description;

- Prismatic element;

- The displacement of the nodal line is described by the displacements of the three nodes of the element, two nodes at each end supporting seven degrees of freedom (for the 3D beam), three 
translations, three rotations and the warping amplitude, plus one node at the mid-length supporting one degree of freedom, namely the non-linear part of the longitudinal displacement;

- The Bernoulli hypothesis is considered, i.e., in bending, plane sections remain plane and perpendicular to the longitudinal axis and no shear deformation is considered;

- No local buckling is taken into account, which is the reason why only Class 1 and Class 2 sections (Greiner 2001) can be analysed;

- The strains are small (von Kármán hypothesis), i.e.

$$
\frac{1}{2} \frac{\partial u}{\partial x} \ll 1
$$

where $u$ is the longitudinal displacement and $x$ is the longitudinal co-ordinate;

- The angles between the deformed longitudinal axis and the undeformed but translated longitudinal axis are small, i.e.,

$$
\sin \varphi \cong \varphi \text { and } \cos \varphi \cong 1
$$

where $\varphi$ is the angle between the arc and the chord of the translated beam finite element;

- The longitudinal integrations are numerically calculated using Gauss' method;

- The cross-section is discretised by means of triangular or quadrilateral fibres. At every longitudinal point of integration, all variables, such as temperature, strain, stress, etc., are uniform in each fibre;

- The tangent stiffness matrix is evaluated at each iteration of the convergence process (pure NewtonRaphson method);

- Residual stresses are considered by means of initial and constant strains (Franssen 1989);

- The material behaviour in case of strain unloading is elastic, with the elastic modulus equal to the Young's modulus at the origin of the stress-strain curve. In the same cross-section, some fibres that have yielded may therefore exhibit a decreased tangent modulus because they are still on the loading branch, whereas, at the same time, some other fibres behave elastically. The plastic strain is presumed not to be affected by a change in temperature (Franssen 1990);

- The elastic torsional stiffness at $20^{\circ} \mathrm{C}$ that is calculated by the code has been adapted in an iterative process in order to reflect the decrease of material stiffness at the critical temperature (Souza and Franssen 2002).

\subsection{Case study}

A simply supported beam-column with span $L$ and fork supports was chosen to explore the validity of the beam-column safety verifications, loaded with end-moments in the major axis and axial compression, as shown in Fig. 1. Regarding the bending moment variation along the member length, three values, $(-1,0$, 1), of the $\psi$ ratio (see Fig. 1) have been investigated. An IPE 220 steel section of grade S235 was used, with a uniform temperature distribution in the cross section.

A lateral geometric imperfection given by the following expression was considered:

$$
y(x)=\frac{l}{1000} \sin \left(\frac{\pi x}{l}\right)
$$




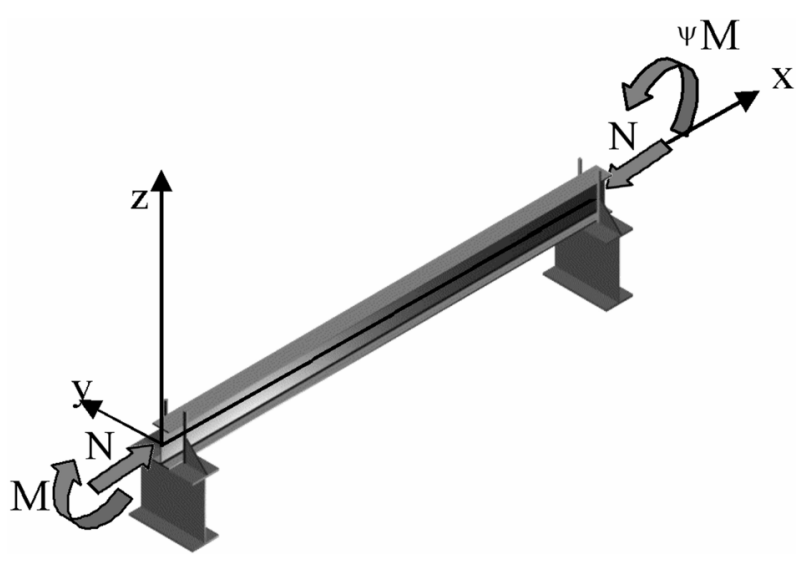

Fig. 1 Simply supported beam with bending and axial compression

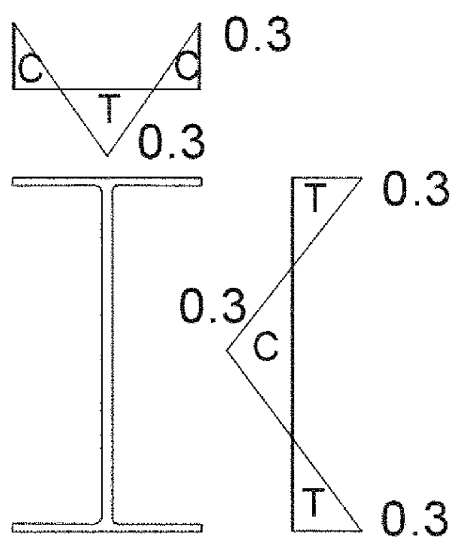

Fig. 2 Residual stresses: C - compression; T - tension

This initial imperfection was imposed in the $\mathrm{x} 0 \mathrm{z}$ plane for the case of full restraint against lateral torsional-bucking, while for members with lateral torsional-buckling the imperfection was considered in the $\mathrm{x} 0 \mathrm{y}$ plane. In the later case an initial rotation was also introduced with a value of $l / 1000 \mathrm{rad}$.

Finally, the adopted residual stresses are constant across the thickness of the web and flanges. A triangular distribution as shown in Fig. 2, with a maximum value of $0.3 \times 235 \mathrm{MPa}$, for the $\mathrm{S} 235$ steel has been used (ECCS 1984).

\section{Interaction formulae for the stability of beam-columns}

\subsection{Generalities}

In most practical applications, the stability of beam-columns is checked by applying interaction formulae based on the modelling of simply-supported single span members with end fork conditions and with or without intermediate lateral restraints, which are subjected to end-moments and transverse loads, to individual single span members regarded as cut out of the system (Villette 2000).

In the following, the various proposals at room and high temperatures are described in detail, for bending about the major axis and axial force.

3.2. Interaction formulae at room and high temperatures based on ENV 1993-1-1/prEN 1993-1-2 proposals

At room temperature, elements with cross-sectional classes 1 and 2 subjected to bending and axial compression must satisfy the following conditions (EUROCODE 3, 1992):

$$
\frac{N_{S d}}{\chi_{\min } A \frac{f_{y}}{\gamma_{M 1}}}+\frac{K_{y} M_{y, S d}}{W_{p l, y} \frac{f_{y}}{\gamma_{M 1}}} \leq 1
$$




$$
\frac{N_{S d}}{\chi_{z} A \frac{f_{y}}{\gamma_{M 1}}}+\frac{K_{L T} M_{y, S d}}{\chi_{L T} W_{p l, y} \frac{f_{y}}{\gamma_{M 1}}} \leq 1
$$

where

$$
\begin{gathered}
K_{y}=1-\frac{\mu_{y} N_{S d}}{\chi_{y} A \frac{f_{y}}{\gamma_{M 1}}} \text { but } K_{y} \leq 1.5 \\
K_{L T}=1-\frac{\mu_{L T} N_{S d}}{\chi_{z} A \frac{f_{y}}{\gamma_{M 1}}} \text { but } K_{y} \leq 1.0
\end{gathered}
$$

and

$$
\begin{gathered}
\mu_{y}=\bar{\lambda}_{y}\left(2 \beta_{M, y}-4\right)+\left[\frac{W_{p l, y}-W_{e l, y}}{W_{e l, y}}\right] \text { but } \mu_{y} \leq 0.9 \\
\mu_{L T}=0.15 \bar{\lambda}_{z} \beta_{M, y}-0.15 \text { but } \mu_{y} \leq 0.9
\end{gathered}
$$

with

$$
\begin{gathered}
\chi=\frac{1}{\phi+\sqrt{[\phi]^{2}-[\bar{\lambda}]^{2}}} \\
\chi_{L T}=\frac{1}{\phi_{L T}+\sqrt{\left[\phi_{L T}\right]^{2}-\left[\bar{\lambda}_{L T}\right]^{2}}}
\end{gathered}
$$

where

$$
\begin{gathered}
\phi=\frac{1}{2}\left[1+\alpha(\bar{\lambda}-0.2)+(\bar{\lambda})^{2}\right] \text { for } \bar{\lambda}>0.2 \\
\phi_{L T}=\frac{1}{2}\left[1+\alpha_{L T}\left(\bar{\lambda}_{L T}-0.2\right)+\left(\bar{\lambda}_{L T}\right)^{2}\right] \text { for } \bar{\lambda}>0.4
\end{gathered}
$$

in this case, for IPE 220 section:

$$
\alpha_{y}=0.21 \alpha_{z}=0.34
$$

and

$$
\beta_{M, y}=1.8-0.7 \psi
$$

For fire loading, according to the new version of Part 1-2 of Eurocode 3 (2002), Eqs. (3) are modified to give: 


$$
\begin{gathered}
\frac{N_{f i, E d}}{\chi_{\min , f i} A k_{y, \theta} \frac{f_{y}}{\gamma_{M, f i}}}+\frac{K_{y} M_{y, f i, E d}}{W_{p l, y} k_{y, \theta} \frac{f_{y}}{\gamma_{M, f i}}} \leq 1 \\
\frac{N_{f i, E d}}{\chi_{z, f i} A k_{y, \theta} \frac{f_{y}}{\gamma_{M, f i}}}+\frac{K_{L T} M_{y, f i, E d}}{\chi_{L T, f i} W_{p l, y} k_{y, \theta} \frac{f_{y}}{\gamma_{M, f i}}} \leq 1
\end{gathered}
$$

where

$$
\begin{gathered}
K_{y}=1-\frac{\mu_{y} N_{f i, E d}}{\chi_{y, f i} A k_{y, \theta} \frac{f_{y}}{\gamma_{M, f i}}} \text { but } K_{y} \leq 3 \\
K_{L T}=1-\frac{\mu_{L T} N_{f i, E d}}{\chi_{z, f i} A k_{y, \theta} \frac{f_{y}}{\gamma_{M, f i}}} \text { but } K_{L T} \leq 1.0
\end{gathered}
$$

and

$$
\begin{gathered}
\mu_{y}=\left(1.2 \beta_{M, y}-3\right) \bar{\lambda}_{y, \theta}+0.44 \beta_{M, y}-0.29 \text { but } \mu \leq 0.8 \\
\mu_{L T}=0.15 \bar{\lambda}_{z, \theta} \beta_{M, L t}-0.15 \text { but } \mu \leq 0.9
\end{gathered}
$$

with

$$
\begin{gathered}
\chi_{f i}=\frac{1}{\phi_{\theta}+\sqrt{\left[\phi_{\theta}\right]^{2}-\left[\bar{\lambda}_{\theta}\right]^{2}}} \\
\chi_{L T, f i}=\frac{1}{\phi_{L T, \theta}+\sqrt{\left[\phi_{L T, \theta}\right]^{2}-\left[\bar{\lambda}_{L T, \theta}\right]^{2}}}
\end{gathered}
$$

where

$$
\begin{gathered}
\phi_{\theta}=\frac{1}{2}\left[1+\alpha \bar{\lambda}_{\theta}+\left(\bar{\lambda}_{\theta}\right)^{2}\right] \\
\phi_{L T, \theta}=\frac{1}{2}\left[1+\alpha \bar{\lambda}_{L T, \theta}+\left(\bar{\lambda}_{L T, \theta}\right)^{2}\right]
\end{gathered}
$$

and

$$
\alpha=0.65 \sqrt{235 / f y}
$$

with

$$
\begin{gathered}
\bar{\lambda}_{y, \theta}=\bar{\lambda}_{y} \sqrt{\frac{k_{y, \theta}}{k_{E, \theta}}} \quad \bar{\lambda}_{z, \theta}=\bar{\lambda}_{z} \sqrt{\frac{k_{y, \theta}}{k_{E, \theta}}} \\
\bar{\lambda}_{L T, \theta}=\bar{\lambda}_{L T} \sqrt{\frac{k_{y, \theta}}{k_{E, \theta}}}
\end{gathered}
$$


The following values of axial and bending resistance are also defined:

$$
N_{f i, \theta, R d}=A k_{y, \theta} \frac{f_{y}}{\gamma_{M, f i}} \quad M_{y, f i, \theta, R d}=W_{p l, y} k_{y, \theta} \frac{f_{y}}{\gamma_{M, f i}}
$$

In order to compare results, the maximum value of the design moment is divided by the plastic moment resistance at temperature $\theta$. Solving Eqs. (10) for $M_{y, f i, E d}$ and dividing by $M_{y, f i, \theta, R d}$ from Eq. (17), gives:

$$
\begin{aligned}
\frac{M_{y, f i, E d}}{M_{y, f i, \theta, R d}} & \leq \frac{1}{\left(1-\frac{\mu_{y} N_{f i, E d}}{\chi_{y, f i} N_{f i, \theta, R d}}\right)}\left(1-\frac{N_{f i, E d}}{\chi_{\min , f i} N_{f i, \theta, R d}}\right) \\
\frac{M_{y, f i, E d}}{M_{f i, \theta, R d}} & \leq \frac{\chi_{L T}}{\left(1-\frac{\mu_{L T} N_{f i, E d}}{\chi_{z, f i} N_{f i, \theta, R d}}\right)}\left(1-\frac{N_{f i, E d}}{\chi_{z, f i} N_{f i, \theta, R d}}\right)
\end{aligned}
$$

Eq. (10) to (18) are the "EC3, New version" formulae.

\subsection{Interaction formulae at room temperature based on prEN 1993-1-1 proposal}

In the current draft of prEN 1993-1-1 (EUROCODE 3, 2003) the proposed checks for the stability of a beam-column, in the case of strong axis bending (classes 1 and 2), are given by the following interaction formulae:

$$
\frac{N_{E d}}{\chi_{y} \frac{N_{R k}}{\gamma_{M 1}}}+k_{y y} \frac{M_{y, E d}+\Delta M_{y, E d}}{\chi_{L T} \frac{M_{y, R k}}{\gamma_{M 1}}} \leq 1
$$

and

$$
\frac{N_{E d}}{\chi_{z} \frac{N_{R k}}{\gamma_{M 1}}}+k_{z y} \frac{M_{y, E d}+\Delta M_{y, E d}}{\chi_{L T} \frac{M_{y, R k}}{\gamma_{M 1}}} \leq 1
$$

where:

$$
N_{R k}=A f_{y} \text { and } M_{y, R k}=W_{p l, y} f_{y}
$$

and for class 1 and class 2 sections, $\Delta M_{y, E d}$ is equal to zero. $k_{y y}$ and $k_{z y}$ are the interaction factors.

Following the same strategy as before, solving for $M_{y, E d}$ from Eqs. (19) and dividing by $M_{y, R d}$ from Eq. (20), gives the ratio of applied moment versus resisting moment for a given level of axial force:

$$
\frac{M_{y, E d}}{M_{y, R k}} \leq \frac{\chi_{L T}}{k_{y y}}\left(1-\frac{N_{E d}}{\chi_{y} N_{R k}}\right)
$$




$$
\frac{M_{y, E d}}{M_{y, R k}} \leq \frac{\chi_{L T}}{k_{z y}}\left(1-\frac{N_{E d}}{\chi_{z} N_{R k}}\right)
$$

\subsubsection{Determination of the interaction factors using Method 1}

The procedure for the determination of the interaction factors for "method 1" is reported in Annex A of part 1.1 of EC3 and was developed by a French-Belgian team (Villette et al. 2000) by combining theoretical rules and numerical calibration to account for all the differences between the real model and the theoretical one. Without attempting at explaining the background of this proposal (EUROCODE 3, 1992), the interaction factors are expressed by the following relations:

$$
k_{y y}=c_{m y} c_{m L T} \frac{\mu_{y}}{1-\frac{N_{E d}}{N_{c r, y}}} \frac{1}{c_{y y}} \quad k_{z y}=c_{m y} c_{m L T} \frac{\mu_{z}}{1-\frac{N_{E d}}{N_{c r, y}} c_{z y}} \frac{1}{c_{z y}} 0.6 \sqrt{\frac{w_{y}}{w_{z}}}
$$

where:

$$
\mu_{y}=\frac{1-\frac{N_{E d}}{N_{c r, y}}}{1-\chi_{y} \frac{N_{E d}}{N_{c r, y}}} \text { and } \quad \mu_{z}=\frac{1-\frac{N_{E d}}{N_{c r, z}}}{1-\chi_{z} \frac{N_{E d}}{N_{c r, z}}}
$$

with

$$
w_{y}=\frac{W_{p l, y}}{W_{e l, y}} \leq 1.5 \quad \text { and } \quad w_{z}=\frac{W_{p l, z}}{W_{e l, z}} \leq 1.5
$$

The coefficients $c_{y y}$ and $c_{z y}$ were obtained by means of numerical calibrations and are given by the following expressions:

$$
\begin{gathered}
c_{y y}=1+\left(w_{y}-1\right)\left[\left(2-\frac{1.6}{w_{y}} c_{m y}^{2} \bar{\lambda}_{\max }-\frac{1.6}{w_{y}} c_{m y}^{2} \bar{\lambda}_{\max }^{2}\right) n_{p l}\right] \geq \frac{W_{e l, y}}{W_{p l, y}} \\
c_{z y}=1+\left(w_{y}-1\right)\left[\left(2-14 \frac{c_{m y}^{2} \bar{\lambda}_{\max }^{2}}{w_{y}^{5}}\right) n_{p l}\right] \geq 0.6 \sqrt{\frac{w_{y}}{w_{z}}} \frac{W_{e l, y}}{W_{p l, y}}
\end{gathered}
$$

where

$$
c_{m y}=c_{m y, 0}+\left(1-c_{m y, 0}\right) \frac{\sqrt{\varepsilon_{y}} a_{L T}}{1+\sqrt{\varepsilon_{y}} a_{L T}}
$$

and

$$
\begin{gathered}
c_{m L T}=c_{m y}^{2} \frac{a_{L T}}{\sqrt{\left(1-\frac{N_{E d}}{N_{c r, z}}\right)\left(1-\frac{N_{E d}}{N_{c r, T}}\right)}} \\
c_{m y, 0}=0.79+0.21 \psi+0.36(\psi-0.33) \frac{N_{E d}}{N_{c r, y}}
\end{gathered}
$$


with:

and

$$
a_{L T}=1-\frac{I_{T}}{I_{y}} \geq 0
$$

$$
\varepsilon_{y}=\frac{M_{y, E d}}{N_{E d}} \frac{A}{W_{e l, y}}
$$

finally:

$$
N_{c r, y}=\frac{\pi^{2} E I_{y}}{l_{y}^{2}} ; N_{c r, z}=\frac{\pi^{2} E I_{z}}{l_{z}^{2}} \quad \text { and } \quad N_{c r, T}=\frac{1}{i_{0}^{2}}\left[G I_{T}+\frac{\pi^{2} E I_{w}}{l_{T}^{2}}\right]
$$

and

$$
i_{0}^{2}=i_{y}^{2}+i_{z}^{2}+y_{0}^{2}+z_{0}^{2} \quad \text { where } \quad y_{0}=z_{0}=0
$$

\subsubsection{Determination of the interaction factors using Method 2}

"Method 2" is described in Annex B of part 1.1 of EC3 (EUROCODE 3, 2002) and results from an Austrian-German proposal that attempted to simplify the verification of the stability of beam-columns, all interaction factors being obtained by means of numerical calibration. These factors are not clearly understandable from a physical point of view, but this simple formulation reduces the possibility of mistakes.

According to this approach, the interaction factors are expressed by the following relations

$$
k_{y y}=c_{m y}\left(1+\left(\bar{\lambda}_{y}-0.2\right) \frac{N_{E d}}{\chi_{y} \frac{N_{R k}}{\gamma_{M 1}}}\right) \leq c_{m y}\left(1+0.8 \frac{N_{E d}}{\chi_{y} \frac{N_{R k}}{\gamma_{M 1}}}\right)
$$

and

$$
\begin{aligned}
k_{z y}= & \left(1-\frac{0.1 \bar{\lambda}_{z}}{\left(c_{m L T}-0.25\right)} \frac{N_{E d}}{\chi_{z} \frac{N_{R k}}{\gamma_{M 1}}}\right) \geq\left(1-\frac{0.1}{\left(c_{m L T}-0.25\right)} \frac{N_{E d}}{\chi_{z} \frac{N_{R k}}{\gamma_{M 1}}}\right) \\
& \text { for } \bar{\lambda}_{z}<0.4: \\
& \left(1-\frac{0.1 \bar{\lambda}_{z}}{\left(c_{m L T}-0.25\right)} \frac{N_{E d}}{\chi_{z} \frac{N_{R k}}{\gamma_{M 1}}}\right) \geq 0.6+\bar{\lambda}_{z}
\end{aligned}
$$

with

$$
c_{m y}=c_{m L T}=0.6+0.4 \psi \geq 0.4
$$

3.4. Proposed interaction formulae at high temperature: "Method 1, fi" and "Method 2, fi"

With the objective of providing a consistent safety format for the evaluation of the stability of beamcolumns under fire loading, Eqs. (19) were adopted as the basis for the proposed expressions. Naturally, 
because of the effect of high temperatures, the following modifications had to be introduced, in line with the procedure adopted in (EUROCODE 3, 2002) for compressed columns or beams in bending: - reduction factors $k_{y, \theta}$ and $k_{E, \theta}$ for yield stress and Young's modulus, at temperature $\theta$, given by

$$
f_{y, \theta}=k_{y, \theta} f_{y} \quad \text { and } \quad E_{\theta}=k_{E, \theta} E
$$

- reduction factors $\chi_{f i}$ for flexural bucking around $y y$ and $z z$ axis, and $\chi_{L T, f i}$ for lateral-torsional buckling, respectively, calculated according to (14) and (15).

Leading to the following interaction formulae:

$$
\begin{aligned}
& \frac{N_{f i, E d}}{\chi_{f i, R k}}+k_{y y, f i} \frac{M_{y, f i, E d}+\Delta M_{y, f i, E d}}{\chi_{y, f i} \gamma_{M, f i}} \leq 1 \\
& \frac{M_{y, f i, R k}}{\gamma_{M, f i}} \\
& \frac{N_{f i, E d}}{\chi_{z, f i} \frac{f_{f i, R k}}{\gamma_{M, f i}}}+k_{z y, f i} \frac{M_{y, f i, E d}+\Delta M_{y, f i, E d}}{\chi_{L T, f i} \frac{M_{y, f i, R k}}{\gamma_{M, f i}}} \leq 1
\end{aligned}
$$

\section{Comparative analysis of the various interaction formulae}

\subsection{Parametric study}

To assess the suitability of Eqs. (38) as the basis of a revised and compatible fire part of EC3, a parametric study was performed that compared the various interaction formulae at high temperatures, Eqs. (10) and (38) with numerical results. To this purpose, for each selected beam-column length and bending moment ratio $\psi$, the interaction Eqs. (10) and (38) were plotted for increasing ratios of $N / N_{f i, \theta, R d}$, together with the results of the numerical simulations for a uniform temperature of $600^{\circ} \mathrm{C}$.

The parametric study covers three alternative bending cases, illustrated in Fig. 3. and the following two situations: no LTB and LTB allowed.

For no LTB, the scope of the parametric study covers 3 bending loading cases and 6 non-dimensional flexural slenderness, $\bar{\lambda}_{y, f i}$.

Figs. 4 to 6 present the corresponding results, for uniform temperature of $600^{\circ} \mathrm{C}$. It is noted that for the proposed interaction Eqs. (38), both methods were applied for the interaction factors.

Analogously, for LTB allowed, the parametric study comprises ten different lengths and the same bending ratios, shown in Figs. 7 to 9.

\section{Conclusions}

For the beam-columns without lateral-torsional buckling and with equal end moments, the three methods are very similar and are not in the safe side. Nevertheless the best results are the ones given by prEN 1993-1-2. For $\psi$ ratio of 0, only the curve from prEN 1993-1-2 is in the safe side. When $\psi$ equals -1 , prEN 1993-1-2 presents better results up to $\bar{\lambda}_{y, f i}=0.58$; from this slenderness onwards the curves obtained with the Method 1 and Method 2 adapted to fire behave better.

When lateral-torsional buckling is considered and $\psi$ equals 1, for lengths between 1000 and $2000 \mathrm{~mm}$, 
"Method 1, fi" is not in the safe side but "Method 2, fi" and the "prEN 1993-1-2" are. For other lengths, the results are very satisfactory. For $\psi$ ratio of 0 and -1 "Method 1, fi" is the best method to approximate the numerical results, all three methods being on the safe side.

Although the results from the prEN 1993-1-2 are a little bit better than the ones obtained with the two methods from prEN 1993-1-1 modified to take in to account the temperature ("Method 1, fi" and "Method 2, fi"), we suggest the use of these two methods. Doing that leads to the same philosophy as the one always presented in the Eurocode 3, i.e., to use the same formulae in both Part 1-1 and Part 1-2 of the Eurocode.
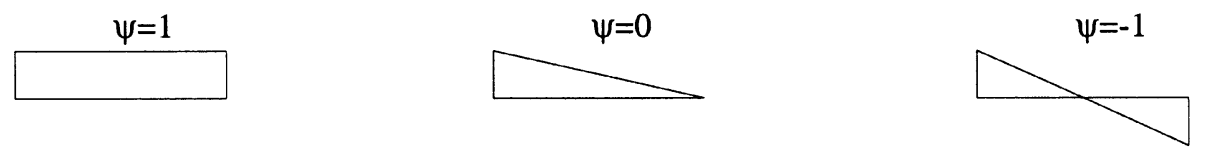

Fig. 3 Studied bending diagrams

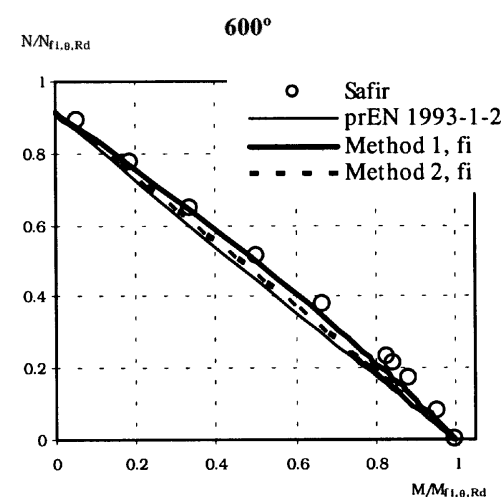

a) $\bar{\lambda}_{y, f i}=0.14 ; \psi=1$

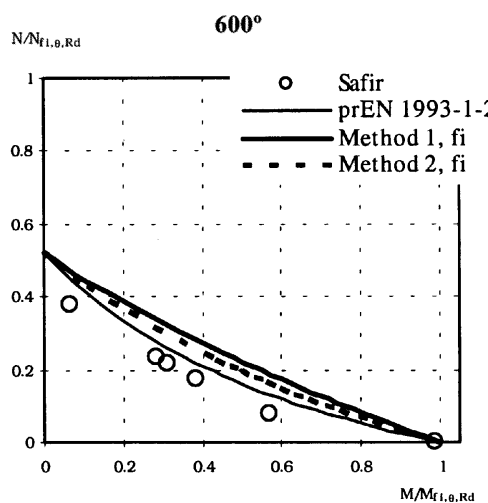

d) $\bar{\lambda}_{y, f i}=0.86 ; \psi=1$

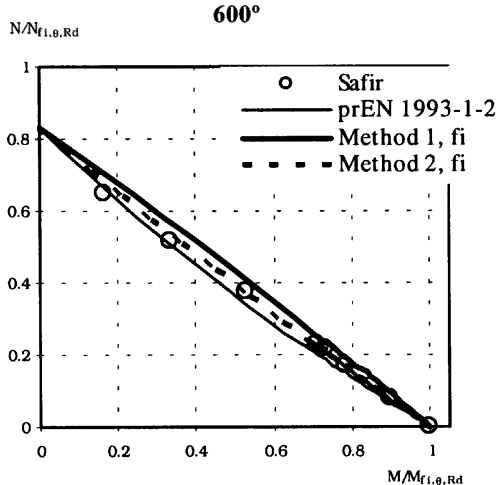

b) $\bar{\lambda}_{y, f i}=0.29 ; \psi=1$

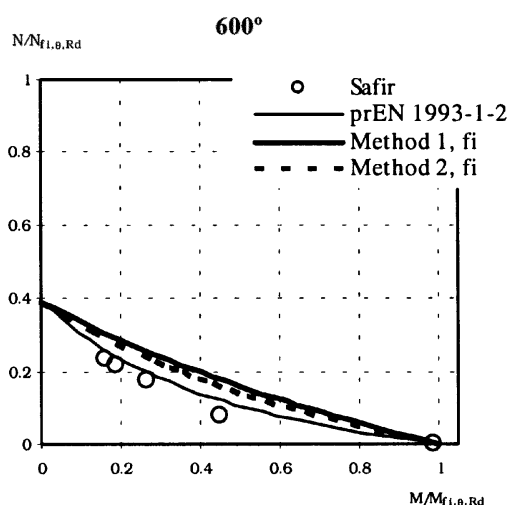

e) $\bar{\lambda}_{y, f i}=1.15 ; \psi=1$

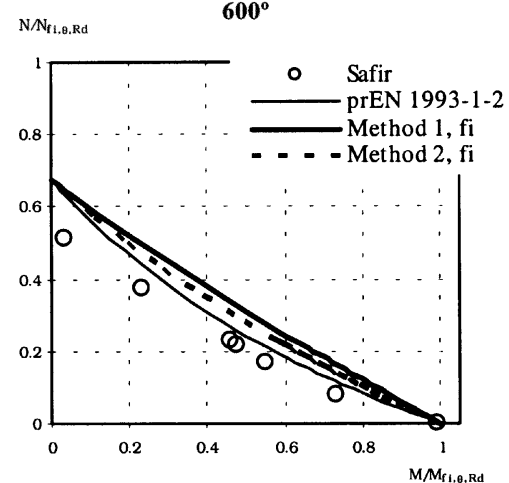

c) $\bar{\lambda}_{y, f i}=0.58 ; \psi=1$

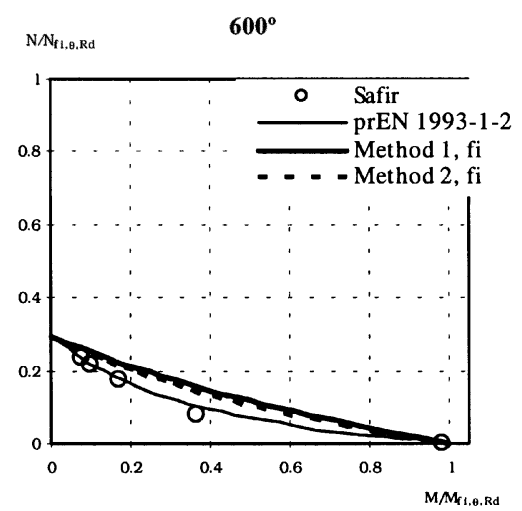

f) $\bar{\lambda}_{y f i}=1.44 ; \psi=1$

Fig. 4 Interaction diagrams for combined moment and axial load at $600{ }^{\circ} \mathrm{C}$, without lateral-torsional buckling for $\psi=1$ 


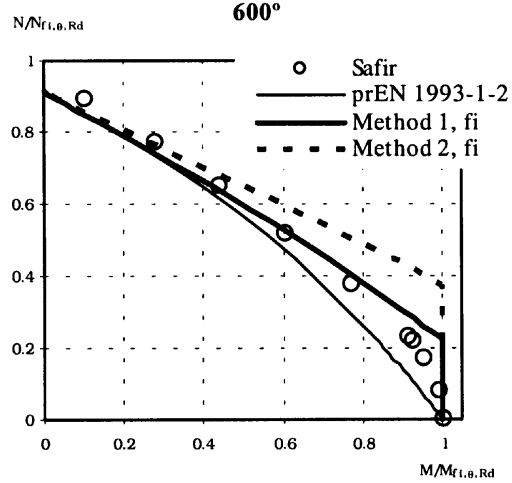

a) $\bar{\lambda}_{y f i}=0.14 ; \psi=0$

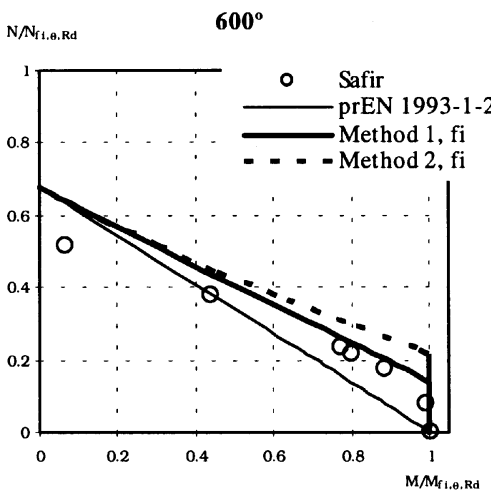

c) $\bar{\lambda}_{y, f i}=0.58 ; \psi=0$

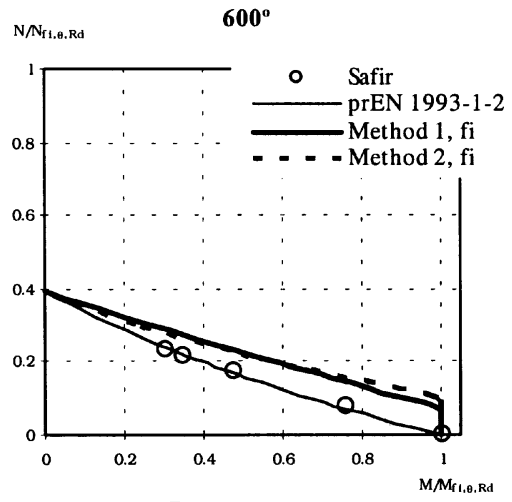

e) $\bar{\lambda}_{y, i}=1.15 ; \psi=0$

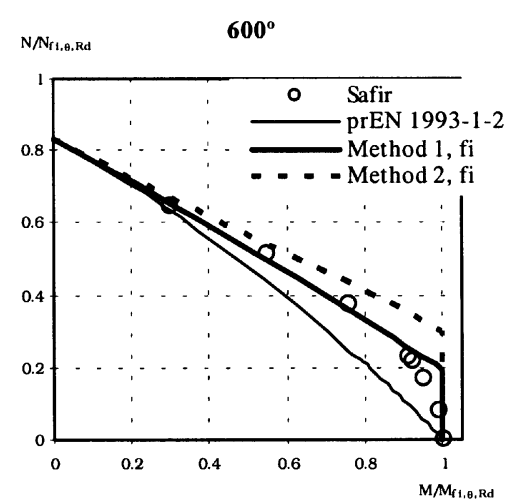

b) $\bar{\lambda}_{y, f i}=0.29 ; \psi=0$

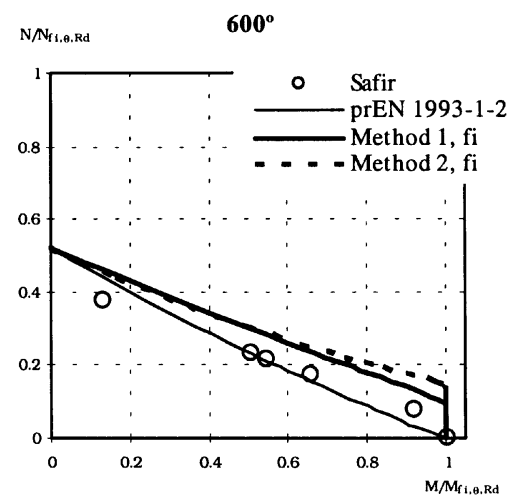

d) $\bar{\lambda}_{y, f i}=0.86 ; \psi=0$

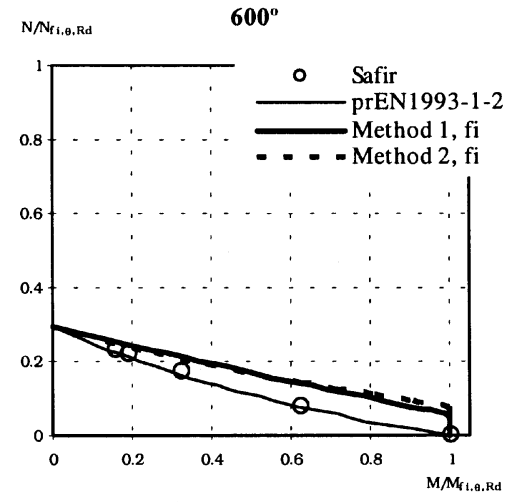

f) $\bar{\lambda}_{y f i}=1.44 ; \psi=0$

Fig. 5 Interaction diagrams for combined moment and axial load at $600{ }^{\circ} \mathrm{C}$, without lateral-torsional buckling for $\psi=0$ 


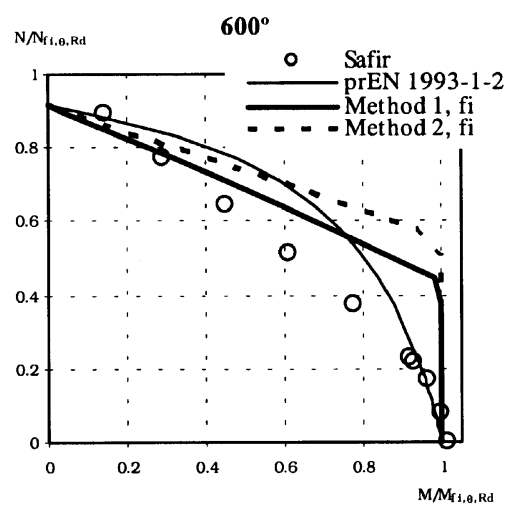

a) $\bar{\lambda}_{y, i}=0.14 ; \psi=-1$

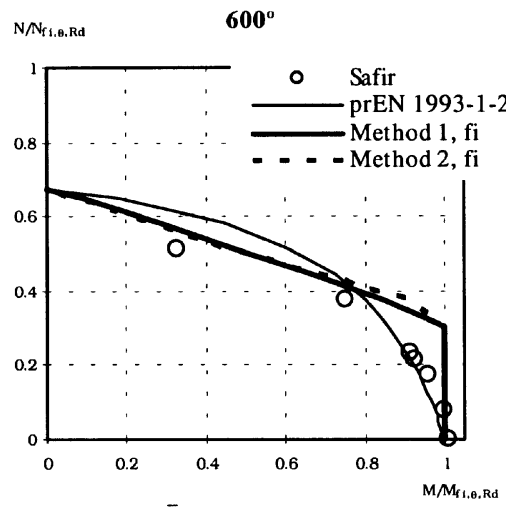

c) $\bar{\lambda}_{y f i}=0.58 ; \psi=-1$

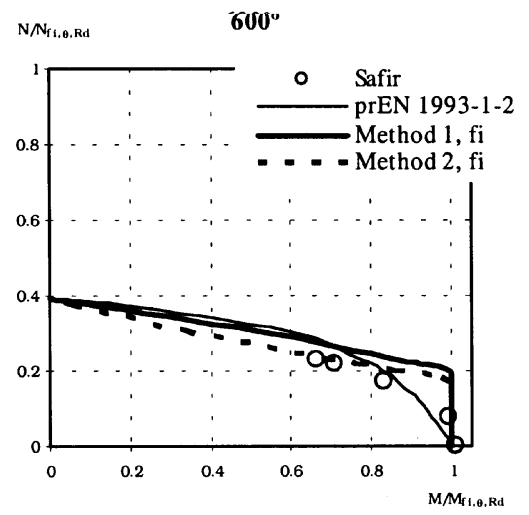

e) $\bar{\lambda}_{y f i}=1.15 ; \psi=-1$

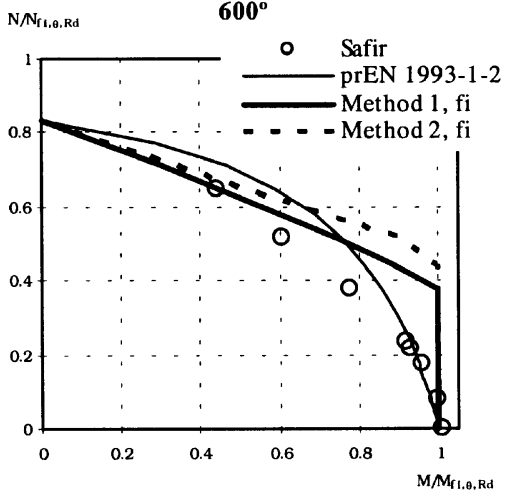

b) $\bar{\lambda}_{y, f i}=0.29 ; \psi=-1$

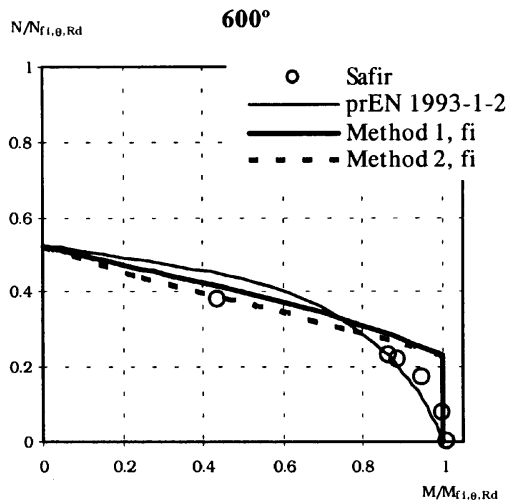

d) $\bar{\lambda}_{y, f i}=0.86 ; \psi=-1$

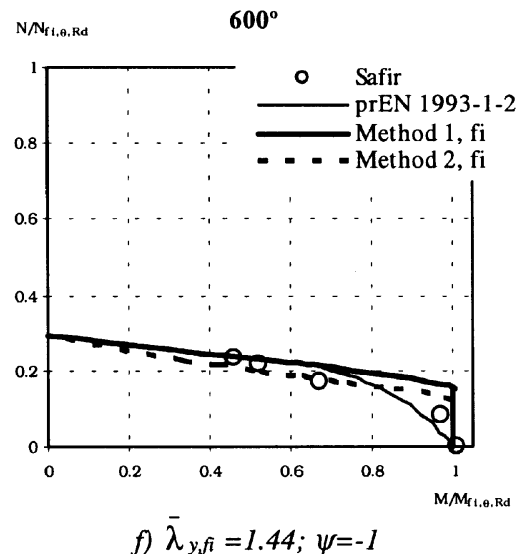

Fig. 6 Interaction diagrams for combined moment and axial load at $600{ }^{\circ} \mathrm{C}$, without lateral-torsional buckling for $\psi=-1$ 


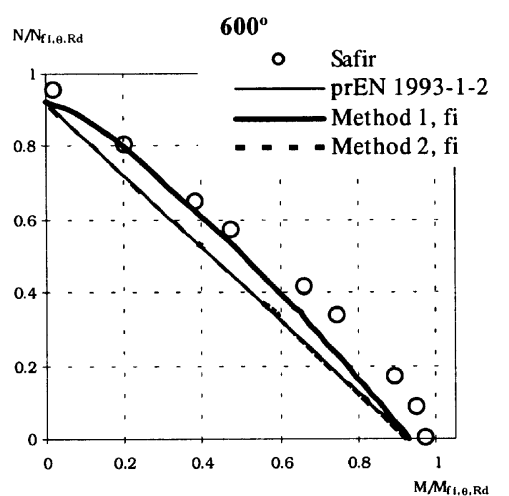

a) $L=250 \mathrm{~mm} ; \bar{\lambda}_{L T f i}=0.12 ; \bar{\lambda}_{y f i}=0.04$; $\bar{\lambda}_{z f i}=0.13 ; \psi=1$

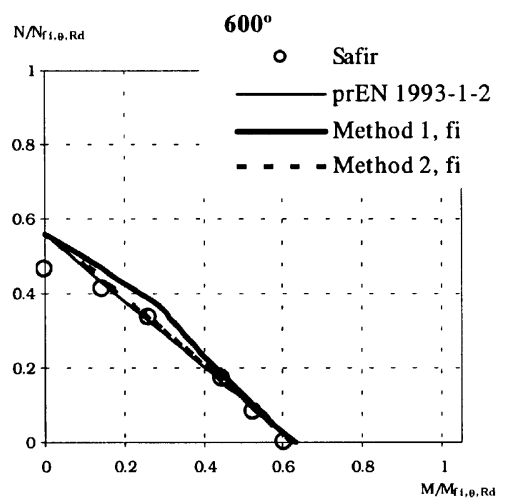

d) $L=1500 \mathrm{~mm} ; \bar{\lambda}_{L T f i}=0.66 ; \bar{\lambda}_{y, f i}=0.22$; $\bar{\lambda}_{z f i}=0.79 ; \psi=1$

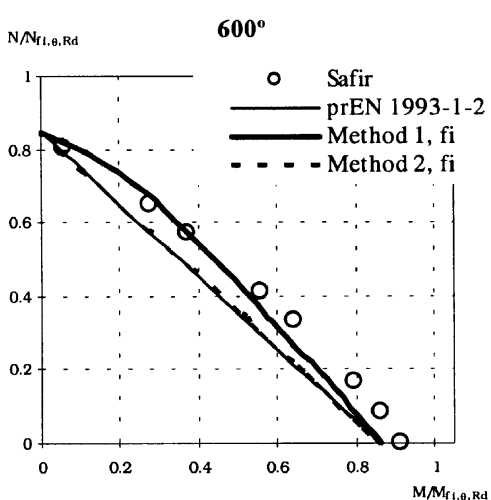

b) $L=500 \mathrm{~mm} ; \bar{\lambda}_{L T f i}=0.24 ; \bar{\lambda}_{y f i}=0.07$; $\bar{\lambda}_{z f i}=0.26 ; \psi=1$

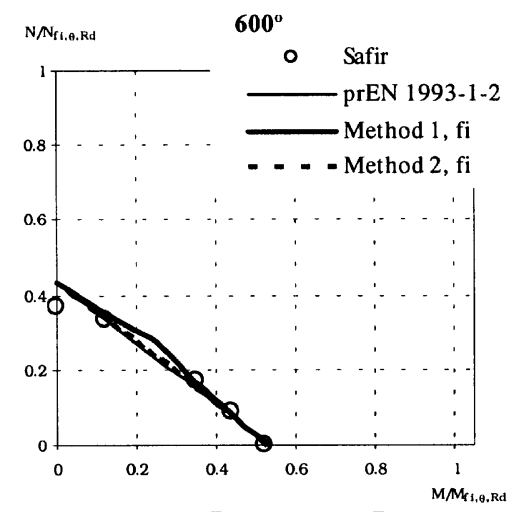

e) $L=2000 \mathrm{~mm} ; \bar{\lambda}_{L T, f i}=0.85 ; \bar{\lambda}_{y, f i}=0.29$; $\bar{\lambda}_{z f i}=1.06 ; \psi=1$

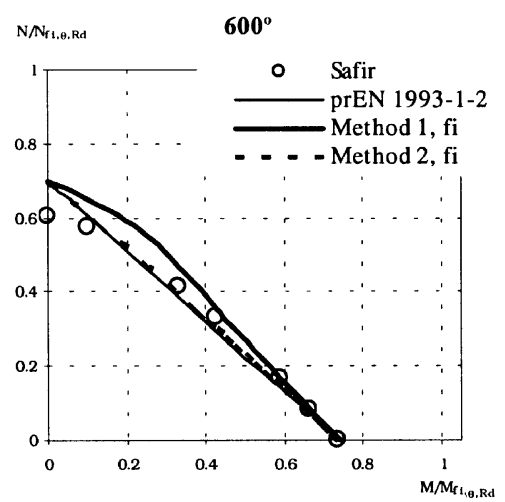

c) $L=1000 \mathrm{~mm} ; \bar{\lambda}_{L T, f i}=0.46 ; \bar{\lambda}_{y, f i}=0.14$; $\bar{\lambda}_{z f i}=0.53 ; \psi=1$

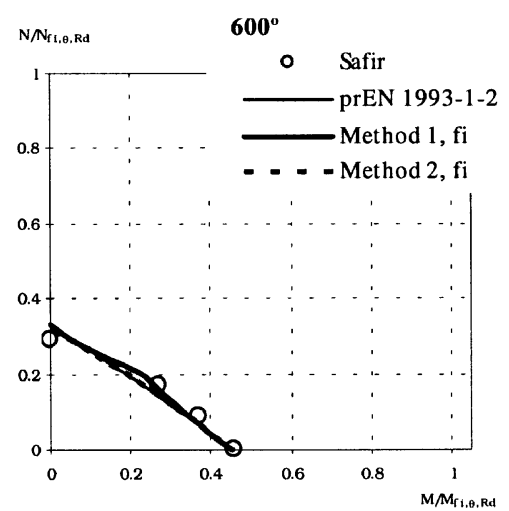

f) $L=2500 \mathrm{~mm} ; \bar{\lambda}_{L T, f i}=1.01 ; \bar{\lambda}_{y, f i}=0.36$; $\bar{\lambda}_{z f i}=1.32 ; \psi=1$

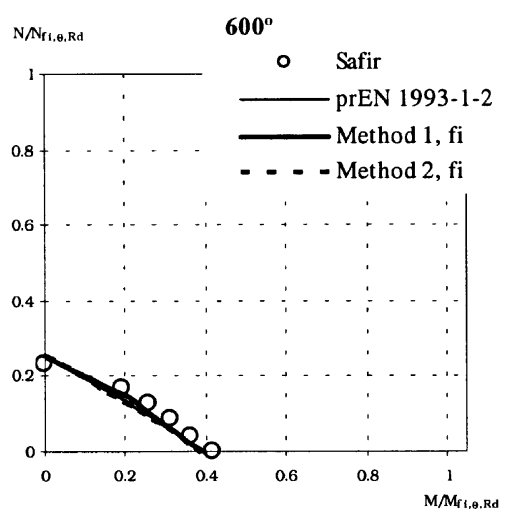

g) $L=3000 \mathrm{~mm} ; \bar{\lambda}_{L T_{f} i}=1.15 ; \bar{\lambda}_{y, f i}=0.43$;

$$
\bar{\lambda}_{z f i}=1.59 ; \psi=1
$$

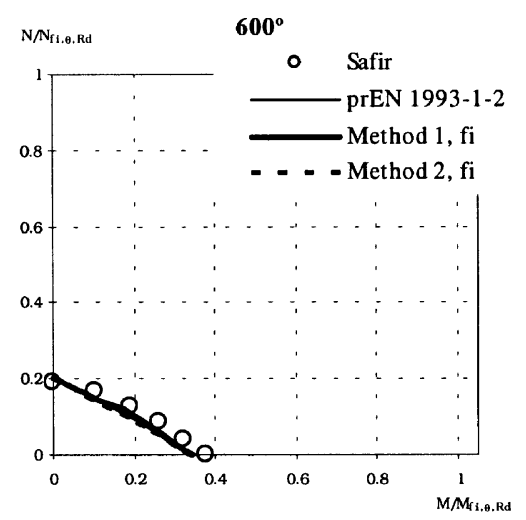

h) $L=3500 \mathrm{~mm} ; \bar{\lambda}_{L T, f i}=1.28 ; \bar{\lambda}_{y, f i}=0.50$; $\bar{\lambda}_{z f i}=1.85 ; \psi=1$

Fig. 7 Interaction diagrams for combined moment and axial load at $600{ }^{\circ} \mathrm{C}$, with lateral-torsional buckling for $\psi=1$ 


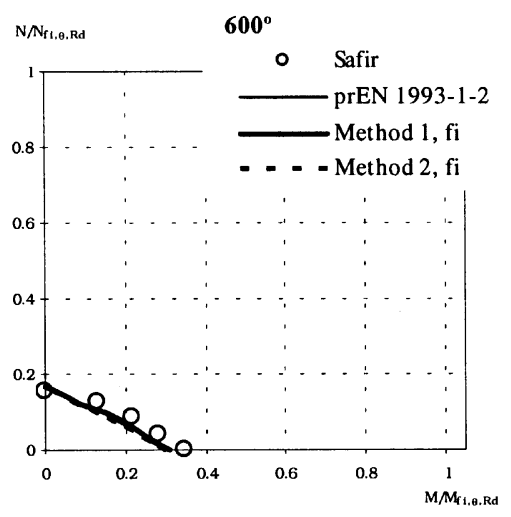

i) $L=4000 \mathrm{~mm} ; \bar{\lambda}_{L T, f i}=1.40 ; \bar{\lambda}_{y f i}=0.58$ $\bar{\lambda}_{z f i}=2.12 ; \psi=1$

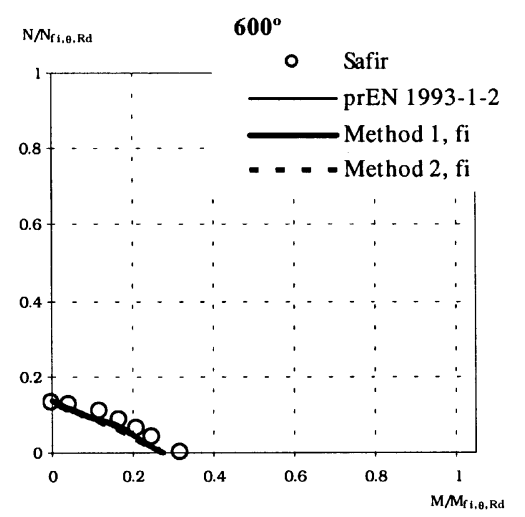

j) $L=4500 \mathrm{~mm} ; \bar{\lambda}_{L T, f i}=1.50 ; \bar{\lambda}_{y f i}=0.65$; $\bar{\lambda}_{z f i}=2.38 ; \psi=1$

Fig. 7 continued

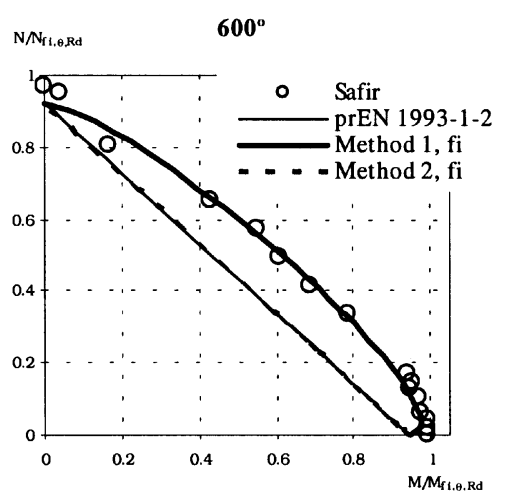

a) $L=250 \mathrm{~mm} ; \bar{\lambda}_{L T f i}=0.09 ; \bar{\lambda}_{y, f i}=0.04$; $\bar{\lambda}_{z f i}=0.13 ; \psi=0$

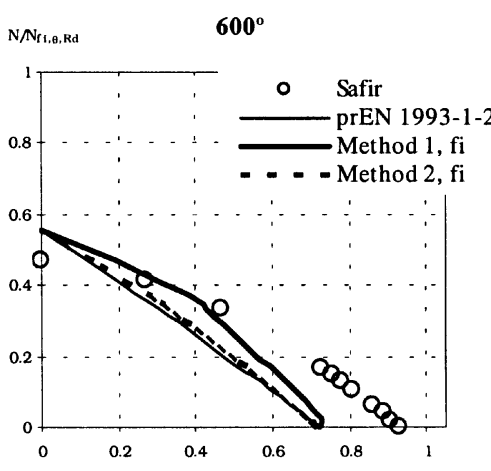

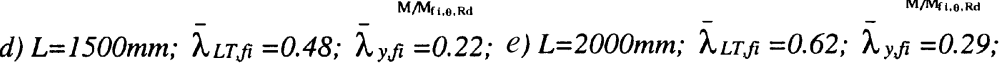
$\bar{\lambda}_{z, f i}=0.79 ; \psi=0$

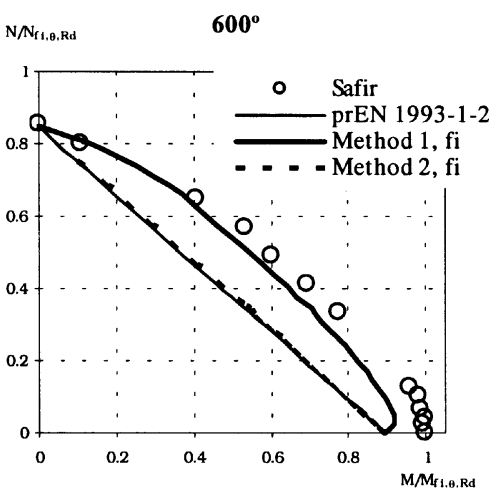

b) $L=500 \mathrm{~mm} ; \bar{\lambda}_{L T, f i}=0.17 ; \bar{\lambda}_{y, f i}=0.07$; $\bar{\lambda}_{z f i}=0.26 ; \psi=0$

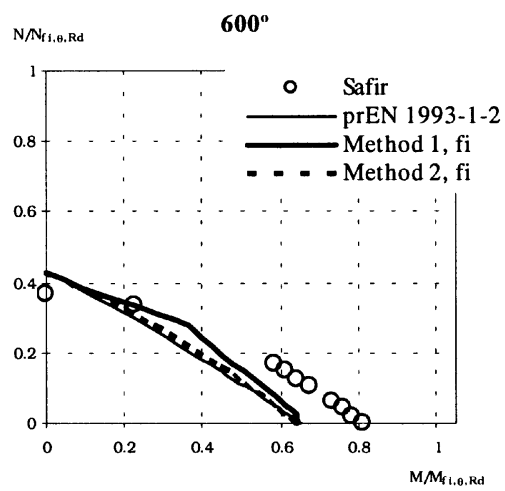

$\bar{\lambda}_{z f i}=1.06 ; \psi=0$

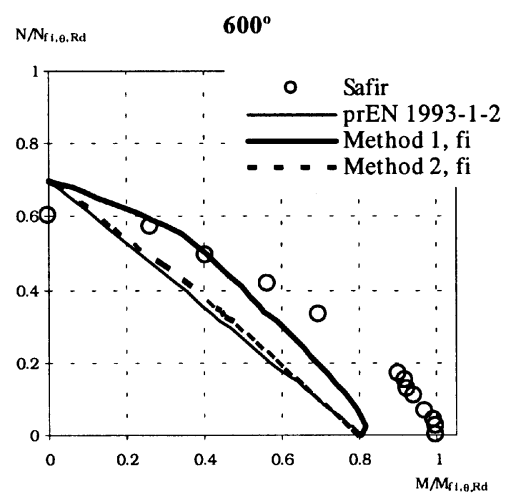

c) $L=1000 \mathrm{~mm} ; \bar{\lambda}_{L T f i}=0.34 ; \bar{\lambda}_{y, f i}=0.14$ $\bar{\lambda}_{z f i}=0.53 ; \psi=0$

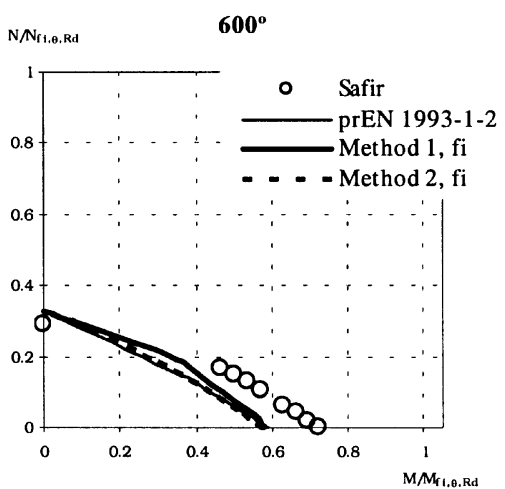

f) $L=2500 \mathrm{~mm} ; \bar{\lambda}_{L T_{i} f}=0.73 ; \bar{\lambda}_{y, f i}=0.36$; $\bar{\lambda}_{z f i}=1.32 ; \psi=0$

Fig. 8 Interaction diagrams for combined moment and axial load at $600{ }^{\circ} \mathrm{C}$, with lateral-torsional buckling for $\psi=0$ 


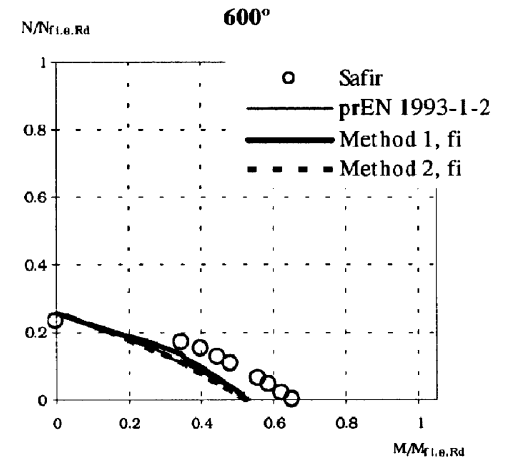

g) $L=3000 \mathrm{~mm} ; \bar{\lambda}_{L T, f i}=0.84 ; \bar{\lambda}_{y, f i}=0.43$; $\bar{\lambda}_{z, i}=1.59 ; \psi=0$

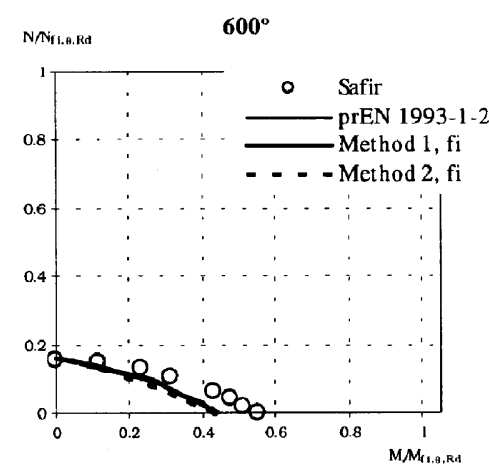

i) $L=4000 \mathrm{~mm} ; \bar{\lambda}_{L T f f i}=1.02 ; \bar{\lambda}_{y_{f} f}=0.58$; $\bar{\lambda}_{z f i}=2.12 ; \psi=0$

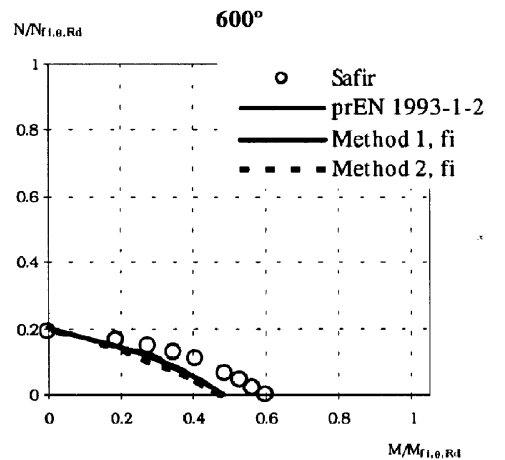

h) $L=3500 \mathrm{~mm} ; \bar{\lambda}_{L T, f i}=0.93 ; \bar{\lambda}_{y f f}=0.50$; $\bar{\lambda}_{z, i}=1.85 ; \psi=0$

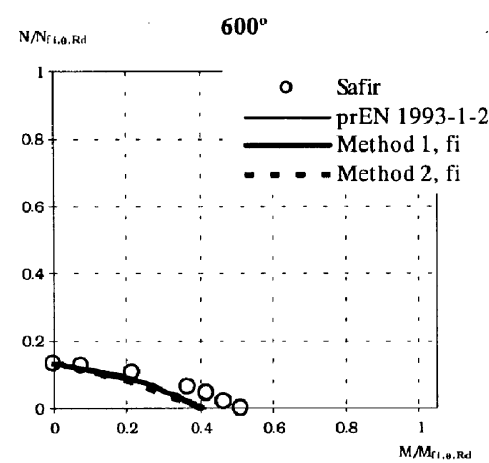

j) $L=4500 \mathrm{~mm} ; \bar{\lambda}_{L T f i}=1.10 ; \bar{\lambda}_{y f i}=0.65$; $\bar{\lambda}_{z f i}=2.38 ; \psi=0$

Fig. 8 continued

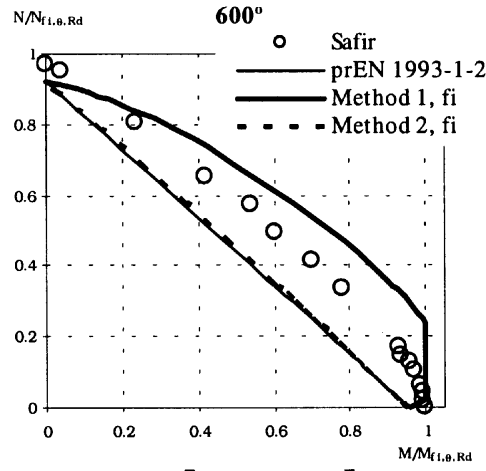

a) $L=250 \mathrm{~mm} ; \bar{\lambda}_{L T f i}=0.07 ; \bar{\lambda}_{y f i}=0.04$; $\bar{\lambda}_{z f i}=0.13 ; \psi=-1$

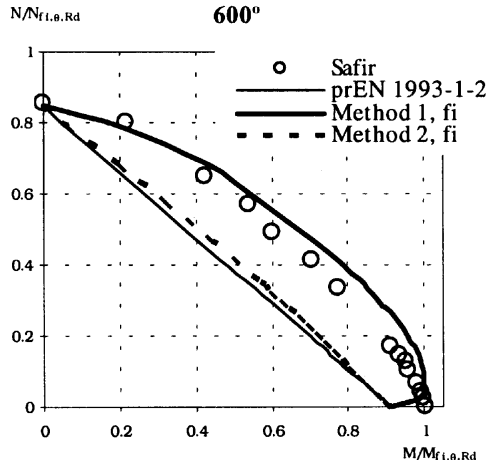

b) $L=500 \mathrm{~mm} ; \bar{\lambda}_{L T, f i}=0.14 ; \bar{\lambda}_{y, f i}=0.07$; $\bar{\lambda}_{z f i}=0.26 ; \psi=-1$

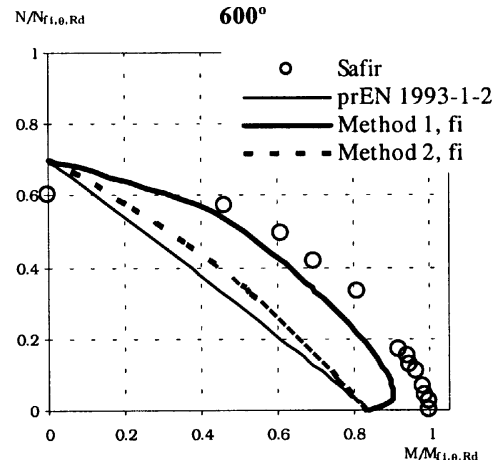

c) $L=1000 \mathrm{~mm} ; \bar{\lambda}_{L T, f i}=0.28 ; \bar{\lambda}_{y, f i}=0.14$; $\bar{\lambda}_{z, f i}=0.53 ; \psi=-1$

Fig. 9 Interaction diagrams for combined moment and axial load at $600{ }^{\circ} \mathrm{C}$, with lateral-torsional buckling for $\psi=-1$ 


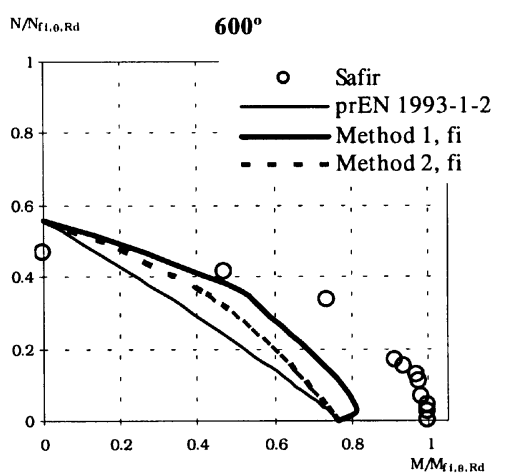

d) $L=1500 \mathrm{~mm} ; \bar{\lambda}_{L T f i}=0.4 ; \bar{\lambda}_{y f i}=0.22$; $\bar{\lambda}_{z f i}=0.79 ; \psi=-1$

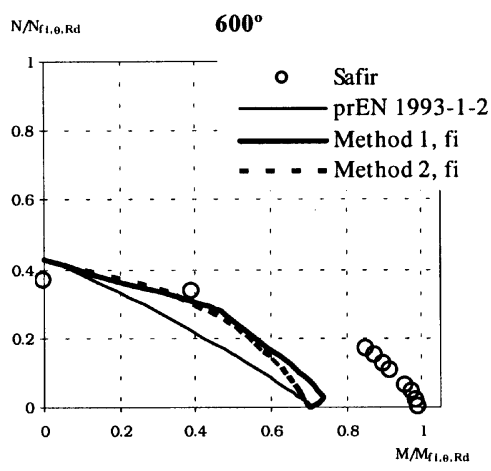

(e) $L=2000 \mathrm{~mm} ; \bar{\lambda}_{L T f i}=0.51 ; \bar{\lambda}_{y, f i}=0.29$; $\bar{\lambda}_{z, f i}=1.06 ; \psi=-1$

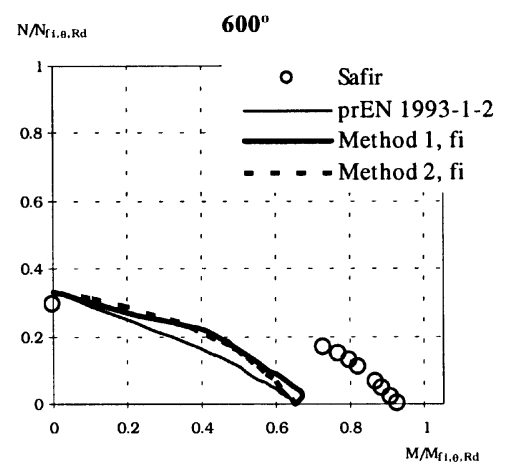

f) $L=2500 \mathrm{~mm} ; \bar{\lambda}_{L T_{1} f}=0.61 ; \bar{\lambda}_{y, f i}=0.36$; $\bar{\lambda}_{z f i}=1.32 ; \psi=-1$

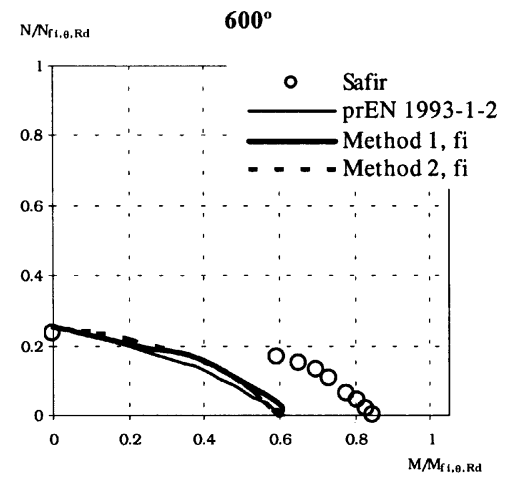

g) $L=3000 \mathrm{~mm} ; \bar{\lambda}_{L T, f i}=0.69 ; \bar{\lambda}_{y, f i}=0.43$; $\bar{\lambda}_{z f i}=1.59 ; \psi=-1$

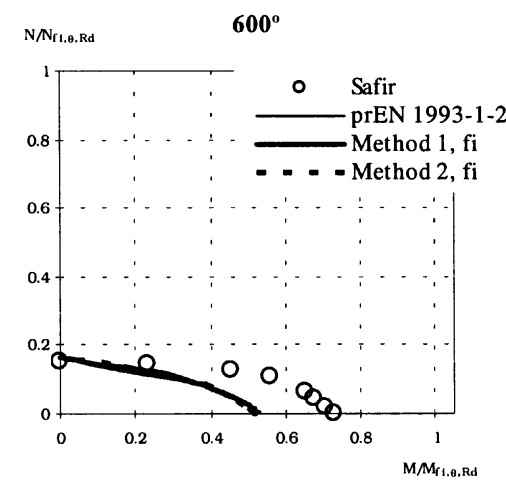

i) $L=4000 \mathrm{~mm} ; \bar{\lambda}_{L T f i}=0.84 ; \bar{\lambda}_{y f i}=0.58$; $\bar{\lambda}_{z f i}=2.12 ; \psi=-1$

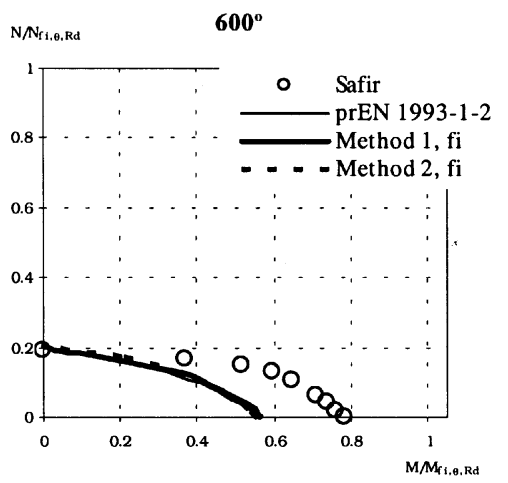

h) $L=3500 \mathrm{~mm} ; \bar{\lambda}_{L T, f i}=0.77 ; \bar{\lambda}_{y, f i}=0.50$; $\bar{\lambda}_{z f i}=1.85 ; \psi=-1$

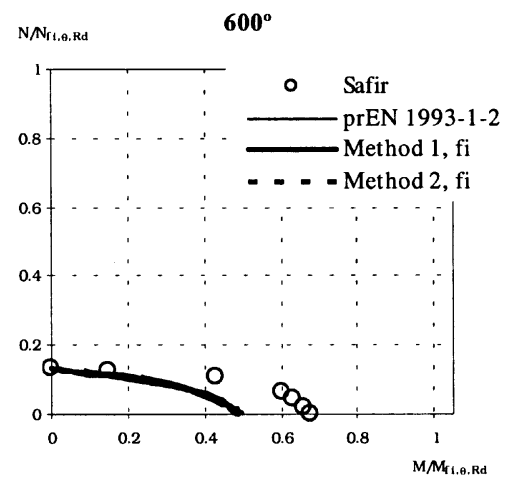

j) $L=4500 \mathrm{~mm} ; \bar{\lambda}_{L T, f i}=0.91 ; \bar{\lambda}_{y, f i}=0.65$; $\bar{\lambda}_{z, i}=2.38 ; \psi=-1$

Fig. 9 continued

Given that codes of practice should present a strong consistency between related checks, it is recommended that the proposed interaction formulae at high temperatures, "Method 1, fi" and "Method 2 , fi", are adopted, resulting in a consistent and logical safety format for the stability of beam-columns both at room and high temperatures. 


\section{References}

Boissonnade, N., Jaspart, J.-P., Muzeau, J.-P. and Villette, M. (2002), "New interaction formulae for beam-columns in Eurocode 3: the French-Belgian approach", Proc. of Third European Conference on Steel Structures Eurosteel 2002, António Lamas and Luís Silva (eds), Coimbra, Portugal, 19-20 September.

ECCS-EUROPEAN CONVENTION FOR CONSTRUCTIONAL STEELWORK (1984), Technical Committee 8 - Structural Stability, Technical Working Group 8.2-System, "Ultimate Limit State Calculation of Sway Frames With Rigid Joints", first edition.

EUROCODE 3 (1992), Design of Steel Structures - part 1-1. General rules and rules for buildings. ENV 1993-1-1, Commission of the European Communities, Brussels, Belgium.

EUROCODE 3 (1995), Design of steel structures - part 1-2: General Rules - Structural fire design, ENV 1993-1-2, Commission of the European Communities, Brussels, Belgium.

EUROCODE 3 (2002), Design of Steel Structures - part 1-2: General Rules - Structural fire design, Draft prEN 1993-1-2, CEN, Brussels, Belgium, February.

EUROCODE 3 (2003), Design of Steel Structures - part 1-1. General rules and rules for buildings. Draft prEN 1993-1-1, Stage 34, CEN, Brussels, Belgium, February.

Franssen, J. M., Taladona, D., Kruppa, J., Cajot, L.G. (1998), "Stability of steel columns in case of fire: experimental evaluation", Journal of Structural Engineering, 124(2), 158-163.

Franssen, J.-M. (1989), "Modelling of the residual stresses influence in the behaviour of hot-rolled profiles under fire conditions", (in French), Construction Métallique, 3, 35-42.

Franssen, J.-M. (2003), "SAFIR. A thermal/structural program modeling structures under fire", Proc. NASCC Conference, American Inst. for Steel Constr., Baltimore, April.

Franssen, J.-M., Schleich, J.-B. and Cajot L.-G. (1995), “A simple model for fire resistance of axially-loaded members according to Eurocode 3", Journal of Constructional Steel Research, Elsevier, 35, 49-69.

Franssen, J.-M., Schleich, J.-B., Cajot, L.-G., Azpiazu, W. (1996), "A simple model for the fire resistance of axially-loaded members-comparison with experimental results", Journal of Constructional Steel Research, Elsevier, 37, 175-204.

Franssen, J.M. (1990), “The unloading of building materials submitted to fire”, Fire Safety Journal, 16, 213-227.

Greiner, R. (2001), "Background information on the beam-column interaction formulae at level 1", ECCS TC 8 Ad-hoc working group on beam-columns paper No.TC8-2001, Technical University Graz, 19 September.

Souza, V., Franssen, J.-M. (2002), "Lateral buckling of steel I beams at elevated temperature comparison between the modelling with beam and shell elements", Proc. 3rd European Conf. On Steel Structures, ISBN: 972-98376-3-5, Coimbra, Univ. de Coimbra, A. Lamas \& L. Simões da Silva ed., 1479-1488.

Vila Real, P.M.M. and Franssen, J.-M. (1999), "Lateral buckling of steel I beams under fire conditions Comparison between the EUROCODE 3 and the SAFIR code", internal report No. 99/02, Institute of Civil Engineering - Service Ponts et Charpents - of the University of Liege.

Vila Real, P.M.M. and Franssen, J.-M. (2001), "Numerical modelling of lateral buckling of steel I beams under fire conditions - comparison with Eurocode 3", Journal of Fire Protection Engineering, USA, 11(2), 112-128.

Vila Real, P.M.M., Piloto, P.A.G. and Franssen, J.-M (2003), "A new proposal of a simple model for the lateraltorsional buckling of unrestrained steel I - beams in case of fire: experimental and numerical validation", Journal of Constructional Steel Research, Elsevier, 59/2, 179-199.

Villette, M., Boissonnade, N., Muzeau, J.P. and Jaspart, J.P. (2000), "Development of a comprehensive formula for the design of beam-columns", internal report (preliminary draft), Bauduin-Châteauneuf, France, C/U/S/T Clermont_Ferrand, France, University of Liege, Department MSM, Belgium, September.

\section{Notation}

$\begin{array}{ll}A & : \text { Area of the cross-section } \\ E & : \text { Young's modulus } \\ f_{y} & : \text { Yield strength } \\ K & : \text { Stiffness of the spring }\end{array}$


$K_{v} \quad:$ Axial stiffness of the beam

$K_{v 0} \quad:$ Axial stiffness of the beam at room temperature

$k_{y y} e k_{z y} \quad:$ Interaction factors that can be determined according to the two methods

$k_{y, \theta} \quad:$ Reduction factor for the yield strength at temperature $\theta_{a}$

$k_{E, \theta} \quad:$ Reduction factor for the slope of the linear elastic range at temperature $\theta_{a}$

$M_{\text {SAFIR }} \quad$ : Resistant moment in the fire design situation given by SAFIR

$M_{y, f i, R d} \quad$ : Design bending moment about $y$ axis for the fire design situation

$M_{y, f i, \theta, R d} \quad$ : Design moment resistance about $y$ axis of a Class 1 or 2 cross-section with a uniform temperature $\theta_{a}$

$N_{f i, E d} \quad$ : Design axial force for the fire design situation

$N_{f i, \theta, E d} \quad$ : Design axial force resistance with a uniform temperature $\theta_{a}$

$W_{e l, y} \quad$ : Elastic section modulus in $y$ axis

$W_{p l, y} \quad$ : Plastic section modulus in $y$ axis

\section{Greek}

$\alpha \quad$ : Imperfection factor and thermal elongation coefficient of steel

$\beta_{M, L T} \quad$ : Equivalent uniform moment factor corresponding to lateral-torsional buckling

$\beta_{M, y} \quad$ : Equivalent uniform moment factor for the $y$ axis

$\Delta M_{y, E d} \quad$ : Moments due to the shift of the centroidal axis, which are equal to zero in case of classes 1,2 and 3

$\gamma_{M 0} \quad$ : Partial safety factor (usually $\gamma_{M 0}=1.0$ )

$\gamma_{M, f i} \quad:$ Partial safety factor for the fire situation (usually $\gamma_{M, f i}=1.0$ )

$\bar{\lambda}_{L T} \quad$ : Non-dimensional slenderness for lateral-torsional bucking at room temperature

$\bar{\lambda}_{y} \quad$ : Non-dimensional slenderness of the $y$ axis for flexural buckling at room temperature

$\bar{\lambda}_{z} \quad$ : Non-dimensional slenderness of the $z$ axis for flexural buckling at room temperature

$\bar{\lambda}_{L T, \theta} \quad$ : Non-dimensional slenderness for lateral-torsional buckling at temperature $\theta_{a}$

$\bar{\lambda}_{y, \theta} \quad:$ Non-dimensional slenderness of the $y$ axis for flexural buckling at temperature $\theta_{a}$

$\bar{\lambda}_{z, \theta} \quad$ : Non-dimensional slenderness of the $z$ axis for flexural buckling at temperature $\theta_{a}$

$\chi_{L T, f i} \quad:$ Reduction factor for lateral-torsional buckling in the fire design situation

$\chi_{\min , f i} \quad:$ Minimum reduction factor of the $y$ and $z$ axis for flexural buckling in the fire design situation

$\chi_{y, f i} \quad:$ Reduction factor of the $y$ axis for flexural buckling in the fire design situation

$\chi_{z, f i} \quad:$ Reduction factor of the $z$ axis for flexural buckling in the fire design situation

CC 